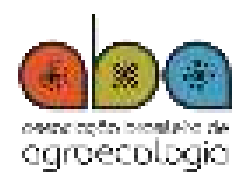

ISSN: $1980-9735$

DOI: 10.33240/rba.v16i3.23469

Vol. 16 | №. 3 | p.249-255 | 2021

\title{
QUALIDADE FITOSSANITÁRIA E GERMINATIVA DE SEMENTES DE FEIJÃO-CAUPI (Vigna unguiculata (L.) WALP.) BIOCONDICIONADAS COM MICRO-ORGANISMOS EFICAZES
}

\author{
Phytosanitary and germinative quality of cowpea seeds \\ (Vigna unguiculata (L.) Walp.) bioconditioned with effective microorganisms
}

Kellen Monique Cabral Dos Santos ${ }^{1}$, Raoni Ribeiro Guedes Fonseca Costa ${ }^{2}$,

Karina Santos Davino ${ }^{3}$ e Ana Flávia De Souza Rocha ${ }^{4}$

${ }^{1}$ Curso de Ciências Biológicas,

Universidade Estadual de Goiás, Campus

Sudoeste-SEDE Quirinópolis, Avenida

Brasil, 435 Conj. - St. Hélio Leão,

Quirinópolis - G0, 75860-000. E-mail:

kellenmonique2009@gmail.com

${ }^{2}$ Curso de Ciências Biológicas,

Universidade Estadual de Goiás, Campus

Sudoeste-SEDE Quirinópolis, Avenida

Brasil, 435 Conj. - St. Hélio Leão,

Quirinópolis - GO, 75860-000. E-mail:

raoniueg@hotmail.com

${ }^{3}$ Curso de Ciências Biológicas,

Universidade Estadual de Goiás, Campus

Sudoeste-SEDE Quirinópolis, Avenida

Brasil, 435 Conj. - St. Hélio Leão,

Quirinópolis - GO, 75860-000. E-mail:

karinadavino2016@gmail.com

${ }^{4}$ CTPP - Centro Tecnológico Paula

Pasquali - Av. Santos Dumont, 124,

Centro, Quirinópolis-GO, 75860-000. Email:

anaflaviadesouza_2012@hotmail.com

Recebido em: 29/03/2021

Aceito para publicação em: 06/06/2021

Correspondência para:

kellenmonique2009@gmail.com

\section{RESUMO}

Objetivou-se avaliar o aspecto fisiológico e sanitário de sementes feijão-caupi, biocondicionadas com micro-organismos eficazes. A avaliação da germinação foi feita no método do papel, enquanto a sanitária realizada pelo método "Blotter-Test". Os resultados indicam a necessidade de cuidados com o armazenamento de 24 meses. A incidência de Aspergillus sp., Rhizopus sp. e um patógeno não identificado, comprometeram $94 \%$ das sementes do controle e $99,5 \%$ das sementes tratadas com micro-organismos eficazes.

Palavras-chave: Agricultura Familiar. Aspergillus sp. Rhizopus sp. Agroecologia.

\section{ABSTRACT}

This work sought to evaluate the physiological and sanitary of cowpea seeds bioconditioned with effective microorganisms.The germination evaluation was made in the paper method, and the sanitary performed by the "Blotter-Test" method The results indicated the need for 24 month storage care.The incidence Aspergillus sp. and Rhizopus sp. and a pathogen (not identified), together compromised $94 \%$ of the seeds of the control and 99.5 of the seeds bioconditioned with effective microorganisms.

Keywords: Family Farming. Aspergillus sp. Rhizopus sp. Agroecology. 
Reconhecido pela sua importância socioeconômica, principalmente nas regiões Norte e Nordeste do Brasil, o feijão-caupi (Vigna unguiculata (L.) Walp.) é uma excelente fonte de proteína, vitaminas e minerais, sobretudo para a agricultura familiar e populações de baixa renda (CARDOSO e RIBEIRO, 2006; FERNANDES et al., 2015).

Esse tipo de feijão apresenta elevada rusticidade e boa adaptação a restrições hídricas, sendo cultivado na Região Nordeste e em áreas com características mais áridas no Centro-Oeste e no Sudeste (particularmente em Mato Grosso e Minas Gerais, respectivamente). Cerca de $86 \%$ da área cultivada no Brasil se encontra no Piauí e Bahia, com um total de 387,5 mil hectares semeados. É uma cultura também utilizada para cultivo consorciado com milho pela agricultura familiar do Pará (CONAB, 2020).

É comum na agricultura familiar que o armazenamento de grãos seja feito em garrafas PET (Polietileno Tereftalato), devido à falta de investimentos para construção de unidades armazenadoras e na capacitação dos agricultores quanto ao armazenamento adequado. Além disso, esses grãos são geralmente utilizados como sementes e, por isso, o armazenamento nesses recipientes deve ser realizado adequadamente, evitando, assim, prejuízos quanto a sua qualidade fisiológica e sanitária (RODRIGUES et al., 2018).

Fungos de armazenamento, interagindo com alguns fatores como danos no tegumento das sementes e umidade inadequada no armazenamento, são os principais agentes de deterioração das sementes. Estes são comumente observados em sementes de feijão e podem afetar a germinação e o vigor quando não são tratadas (ZUCCHI e MELO, 2009). Os principais fungos de armazenamento do feijão são Aspergillus sp., Penicillium sp. e Rhizopus sp., sendo os dois primeiros responsáveis por perdas acima de $30 \%$ de grãos armazenados, podendo causar uma série de injúrias nas sementes como o enfraquecimento ou morte do embrião, além de redução na germinação e emergência (TALAMINI et al., 2010).

$\mathrm{Na}$ agricultura familiar tem se tornando comum a substituição de defensivos agrícolas e fertilizantes químicos industrializados por micro-organismos eficazes (EM). Alguns trabalhos têm demonstrado que o uso do EM, pode proporcionar melhor desempenho agronômico e de produtividade (PORTO et al., 2020; MAGALHAES et al., 2020) e em concentrações adequadas, promover melhores taxas de germinação, emergência e velocidade de emergência de plântulas (MOWA e MASS, 2012; BORGES et al., 2020). O EM é um consórcio de micro-organismos: bactérias produtoras de ácido láctico, leveduras, bactérias fotossintéticas, fungos e actinomicetos, facilmente produzido e de baixo custo, que pode, também, inibir a ação de patógenos (SANTOS et al., 2020; HIMANGINI et al., 2019).

Objetivou-se avaliar a qualidade fisiológica e sanitária de sementes do feijão-caupi (Vigna unguiculata (L.) Walp.) armazenadas em garrafas PET, provenientes da agricultura familiar, bem como verificar o efeito do EM na promoção do vigor dessas sementes.

O experimento foi conduzido no Laboratório Microbiologia Ambiental e Agrícola da Universidade Estadual de Goiás, Campus Sudoeste-Sede Quirinópolis (UEG), em Quirinópolis, Goiás. O lote de sementes de feijão-caupi (Vigna unguiculata (L.) Walp.) de tegumento preto, foi fornecida por um agricultor do município de Santo Antônio da Barra, Goiás, Brasil (1733' de latitude Sul e 5040' de longitude Oeste, a $636 \mathrm{~m}$ de altitude). As sementes estavam armazenadas em uma garrafa PET de dois litros, por um período de 2 anos.

Os EM foram atraídos por "iscas", usando arroz como matéria orgânica. Essas iscas foram preparadas com o cozimento de, aproximadamente, $700 \mathrm{~g}$ do cereal sem sal, que foram colocadas em pranchas de madeira de $15 \times 20 \mathrm{~cm}$ (140 g de arroz por prancha). Cinco pranchas foram instaladas em solo exposto após a retirada total da serapilheira, conforme metodologia de Porto et al. (2020). Após a instalação, uma camada de serapilheira foi adicionada como cobertura e a isca foi coberta com uma fina lona de TNT, colocada sobre suportes de madeira, a fim de proteger contra a ação direta dos pingos de chuva.

A instalação ocorreu em uma reserva legal de Floresta Estacional Semidecidual, localizada na fazenda Fazendinha ( $18^{\circ} 24^{\prime} 22^{\prime \prime}$ Latitude Sul, 5023'34" Longitude Oeste a $544 \mathrm{~m}$ de altitude). A colonização das iscas pela microbiota local foi monitorada diariamente a partir do 11을 dia de incubação. 
A colonização total foi observada no 15 dia de incubação, onde as tábuas foram retiradas e levadas ao Laboratório Microbiologia Ambiental e Agrícola para isolamento de EM.

A seleção das colônias benéficas nas iscas foi feita mantendo somente as que apresentavam as cores rosa, azul, amarela e laranja, descartando as colônias com coloração cinza, marrom e preta, conforme a metodologia apresentada por Bonfim et al. (2011). A ativação dos EM foi feita colocando as colônias selecionadas das cinco pranchas em um tambor plástico de 70 litros, sendo adicionados 5 litros de melaço de cana em 50 litros de água limpa (sem cloro) de poço semiartesiano.

O recipiente foi hermeticamente fechado, mantido à sombra por 25 dias. Para reduzir a pressão do processo fermentativo (anaeróbico) no tambor, este era aberto a cada dois dias. Esse procedimento foi feito durante os 25 dias de fermentação. Finalizado o processo fermentativo (a partir do 260 dia), o inoculante de EM apresentou as características esperadas, coloração alaranjada e odor doce agradável.

As sementes de feijão-caupi foram separadas em dois tratamentos: sementes controle sem biocondicionamento com EM e sementes biocondicionadas com EM. Para avaliação da qualidade fisiológica das sementes, foram realizados os seguintes testes: porcentagem de germinação, índice de velocidade de germinação, índice de velocidade de emergência e determinação da umidade.

$\mathrm{O}$ biocondicionamento com EM foi feito colocando $1,2 \mathrm{~mL}$ de $\mathrm{EM} \mathrm{g}^{-1}$ de semente e, então, dispostas em papel toalha por 1 minuto e, posteriormente, colocadas nos recipientes para teste de germinação.

O teste de germinação foi feito utilizando caixas acrílicas transparentes do tipo Gerbox ${ }^{\circledR}$ $(11 \times 11 \times 3,5 \mathrm{~cm})$ previamente desinfestadas com álcool $70 \%$, em substrato sobre papel (duas folhas de papel mata-borrão), previamente esterilizadas, umedecidas com água destilada na proporção de 2,5 vezes seu peso seco. Para cada tratamento utilizou-se 16 caixas, cada uma com 25 sementes, totalizando 400 sementes por tratamento. As sementes foram levadas ao germinador de câmara modelo Mangelsdorf, com temperatura controlada de 25 으, sendo a germinação avaliada do 1음 ao 8응 dia (BRASIL, 2009a).

O Índice de Velocidade de Germinação (IVG) foi realizado concomitante ao teste de germinação e determinado através da contagem de sementes germinadas do primeiro ao nono dia de avaliação (BRASIL, 2009a). Foram consideradas como germinadas as sementes com radícula de tamanho igual ou superior a $0,2 \mathrm{~cm}$. O IVG foi calculado através do somatório do número de sementes germinadas a cada dia, dividido pelo número de dias decorridos entre a semeadura e a germinação, segundo a fórmula de Maguire (1962).

A emergência em areia foi conduzida com quatro repetições de 25 sementes em caixas plásticas. No substrato entre areia, as sementes foram colocadas a uma profundidade de $1 \mathrm{~cm}$, o umedecimento foi feito com água destilada até atingir 60\% da capacidade de campo (BRASIL, 2009a).

O Índice de Velocidade de Emergência (IVE), foi obtido por meio de contagens diárias. Contou-se as plântulas normais emergidas até a estabilização da emergência, sendo calculado o índice de velocidade de emergência segundo Maguire, (1962).

Para o teste de umidade de sementes foi utilizado o método de estufa a $105^{\circ} \mathrm{C}$, no qual, o grau de umidade de uma amostra é representado pela perda de peso quando esta é submetida à esta temperatura, seguindo a orientação do manual de análises de sementes Brasil (2009a).

O teste de sanidade de sementes realizado foi o "Blotter-test", sendo utilizadas 400 sementes de cada tratamento. Estas foram dispostas equidistantes sobre tripla camada de papel de filtro umedecido, no interior de caixas acrílicas transparentes $(11 \times 11 \times 3,5 \mathrm{~cm})$ tipo Gerbox ${ }^{\circledR}$. Os recipientes contendo as sementes foram dispostos sob lâmpadas de luz branca, em câmaras de germinação com fotoperíodo de 12 horas por período 7 dias à temperatura de $20 \pm 2^{\circ} \mathrm{C}$. As sementes foram examinadas individualmente através de um microscópio estereoscópio. Os resultados foram expressos em percentual de ocorrência dos fungos (BRASIL, 2009b).

Os experimentos foram conduzidos em delineamento inteiramente casualizado (DIC), sendo dois tratamentos (sementes biocondicionadas com EM e controle) com 16 repetições cada e 25 
sementes por repetição. Os dados foram expressos em percentual de germinação, índice de velocidade de germinação e emergência de plântulas, percentual de umidade e de incidência de fungos. Efetuou-se análise de variância dos dados, e para a comparação de médias o teste de Tukey a $5 \%$ de probabilidade, utilizando-se o R (R Core Team, 2020).

Observou-se baixo percentual de germinação, tanto para o tratamento controle $(6,75 \%)$ quanto para as sementes biocondicionadas com EM (0,5\%) (Tabela 1). A baixa germinação no tratamento controle indica que a qualidade fisiológica das sementes já não era adequada aos 2 anos de armazenamento em garrafas PET. Entretanto, essa baixa germinação não está atribuída ao percentual de umidade das sementes que apresentaram nos dois tratamentos $12 \%$.

Tabela 1. Incidência de fitopatógenos e características da germinação de sementes de feijão-caupi (Vigna unguiculata (L.) Walp.), biocondicionadas e não com micro-organismos eficazes. Quirinópolis-GO. .7 de fevereiro de 2021.

\begin{tabular}{lcccccc}
\hline Tratamento & $\begin{array}{c}\text { Aspergillus sp } \\
\text { (\%) }\end{array}$ & $\begin{array}{c}\text { Rhizopus sp } \\
\text { (\%) }\end{array}$ & $\begin{array}{c}\text { Patógeno não } \\
\text { identificado } \\
\text { (\%) }\end{array}$ & \% G & IVG & IVE \\
\hline Controle & $36 \mathrm{~A}$ & $6,25 \mathrm{~A}$ & $52 \mathrm{~A}$ & $6,75 \mathrm{~A}$ & $20,4 \mathrm{~A}$ & $4,03 \mathrm{~A}$ \\
EM & $22 \mathrm{~A}$ & $0,25 \mathrm{~A}$ & $78 \mathrm{~B}$ & $0,5 \mathrm{~B}$ & $1,3 \mathrm{~B}$ & $2,26 \mathrm{~B}$ \\
\hline Erro padrão & 1,09 & 0,46 & 1,34 & 0,99 & 0,90 & 1,33 \\
\hline
\end{tabular}

*EM (micro-organismos eficazes); IVE (Í́ndices de Velocidade de Emergência); IVG (Índice de Velocidade de Germinação); \%G (Porcentagem de Germinação). Médias seguidas pela mesma letra na coluna não diferem significativamente entre si pelo teste de Tukey a $5 \%$.

Em pequenas propriedades, o armazenado de grãos é feito, predominantemente, em garrafas PET, durante 3 meses a 2 anos, sendo observada perdas superiores a 28\% (RODRIGUES et al., 2018), principalmente em razão de problemas relacionados ao armazenamento. A umidade inadequada é um dos fatores que ocasiona maior perda das sementes, podendo estar associada ao atraso na colheita, a elevada umidade e armazenamento com pouca entrada de ar, condições estas que favorecem a proliferação de fungos (SILVA et al., 2021). Entretanto, os teores de umidade nesta pesquisa indicam que as sementes estavam em boas condições de umidade no armazenamento.

O teor de umidade observado no lote de sementes foi de $12 \%$, semelhante aos valores obtidos por Silva (2019), avaliando feijão-caupi produzido no Rio Grande do Norte, onde verificaram umidade variando de $10,52 \%$ a $12,15 \%$. Teores de umidade entre 11 e $13 \%$ são adequados, pois mantém baixa a taxa respiratória e prolonga a manutenção da qualidade do grão armazenado (BRAGANTINI, 2005).

A maioria dos trabalhos avaliam a viabilidade de sementes em um período máximo de 12 meses (RODRIGUES et al., 2018) e tem indicado a boa qualidade fisiológica e vigor das sementes nesse período de armazenamento. Desse modo, podemos supor que o armazenamento prolongado, associado a outras condições inadequadas do armazenamento, como limpeza inadequada do recipiente, falta de tratamento fitossanitário e/ou problemas de transporte, proporcionaram condições desfavoráveis, aumentando a porcentagem de grãos danificados. Esses fatores certamente comprometeram a germinação, o vigor e a sanidade das sementes (RODRIGUES et al., 2018), acarretando o percentual baixo de germinação verificado neste estudo.

$\mathrm{O}$ esperado era de que o EM promovesse maior taxa de germinação nas sementes, entretanto, $\mathrm{O}$ sucesso com o biocondicionamento não se concretizou. As sementes biocondicionadas com EM foram infectadas por um patógeno que comprometeu sua germinação, fato este corroborado pelo índice de velocidade de geminação 20,4 para o controle e 1,3 nas sementes que receberam EM. Da mesma forma, o IVE 4,03 e 2,26 para o tratamento controle e biocondicionadas com EM, respectivamente (Tabela 1).

Algumas pesquisas têm apontado efeito benéfico do uso do EM na promoção da germinação de semente. Borges et al. (2020), avaliando efeito do EM na promoção do vigor em milheto ADR300 verificaram efeito positivo no crescimento da raiz e parte aérea na dosagem de $40 \mathrm{uL}$, porém, destacam a necessidade de atenção quanto à concentração utilizada, pois notaram que doses mais elevadas reduziram a porcentagem de emergência e índice de velocidade de emergência das plântulas, bem 
como reduziram o crescimento da parte aérea e do sistema radicular. Isso foi apresentado por Santos et al. (2020), avaliando efeito do EM na germinação do capim-paliçada, verificaram que o tempo de exposição e maior concentração de EM, podem reduzir o percentual de germinação.

Em relação à incidência de fungos deterioradores, no "blotter teste", Aspergillus sp. foi observado em $22 \%$ e Rhizopus sp. em 0,25\% das sementes biocondicionadas com EM (Tabela 1 e Figura 2 a e b). Nas sementes controle, foi observada a incidência de Aspergillus sp. em 36\% e Rhizopus sp. em $6,25 \%$.
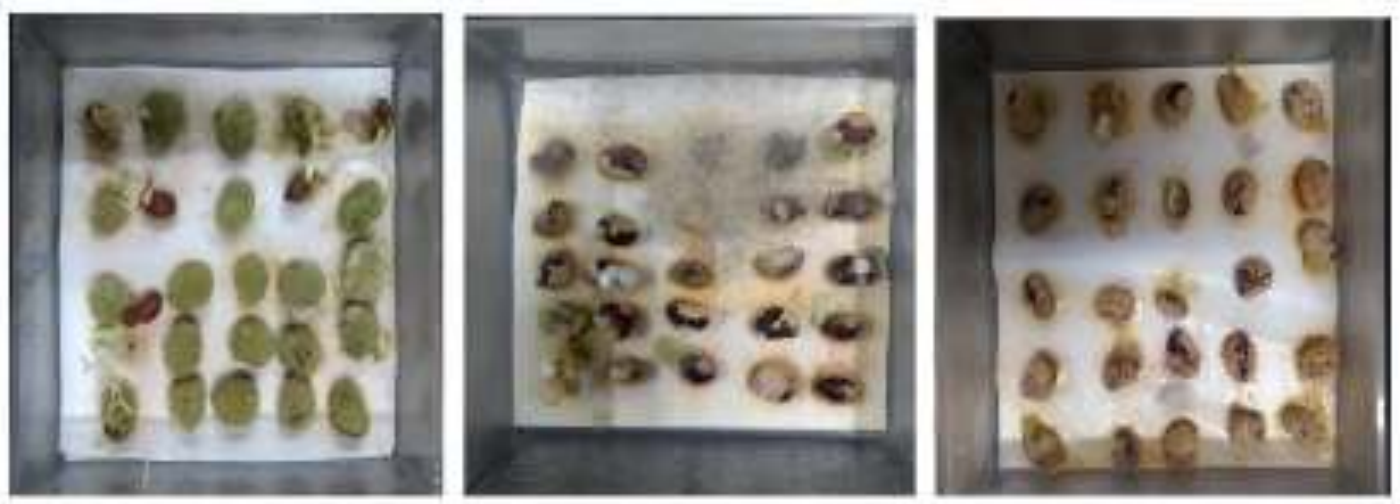

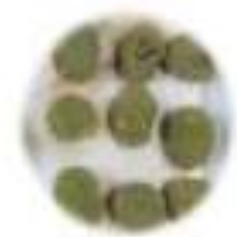

a) Aspengillus sy

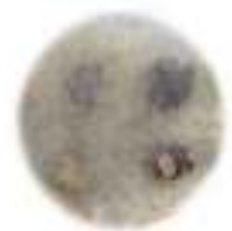

b) Rhizonous sp

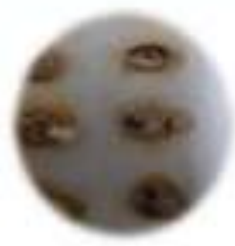

c) pałógeno nāo identificado

Figura 1. Sementes de feijão-caupi inoculadas com micro-organismos eficazes, com incidência de a) Aspergillus sp., b) Rhizopus sp. e c) patógeno não identificado, observados após 7 dias de incubação a $25^{\circ} \mathrm{C}$ no método "Blotter-Test" Quirinópolis-GO.7 de fevereiro de 2021.

Verificou-se a proliferação de um patógeno oportunista (Tabela 1, Figura 2-c) que comprometeu a porcentagem de germinação em $78 \%$ do tratamento utilizando EM e $52 \%$ no controle. Estes formaram colônias no tegumento. A princípio, poderia se tratar de um micro-organismo componente do próprio EM, pois desde o terceiro dia do teste de sanidade observou-se uma película branca aumentando sua extensão no quarto dia e progredindo para uma estrutura rugosa e mais escurecida sobre o tegumento no sétimo dia de avaliação (Figura 2-c). Entretanto, esse mesmo patógeno foi observado no tratamento controle, indicando contaminação prévia na semente.

Sementes de feijão têm sido relatadas como fonte de contaminação por fungos de armazenamento, o que foi verificado neste estudo. Talamini et al. (2010), ao avaliarem a qualidade fisiológica e sanitária de sementes de feijão comum (Phaseolus vulgaris L.) produzidas por agricultores familiares, observaram Aspergillus sp. com percentual de incidência variando de 19,5 a 31\% e Rhizopus sp. 3 a 15,5\% em dez lotes de sementes analisados, foi constatada, também, baixa germinação das sementes, tendo a maioria dos lotes um percentual inferior a $80 \%$, chegando, em alguns casos, a $24 \%$.

Supomos que, no tratamento controle, os fungos Aspergillus sp. e Rhizopus sp. apresentaram maior capacidade de competição e inibiram o crescimento do patógeno que somente foram observadas a partir do 4으 dia, e em menor incidência. A identificação desse patógeno é importante tendo em vista o alto percentual de inibição na germinação das sementes.

A incidência de Aspergillus sp. em feijão-caupi, foi verificada por Silva et al. (2014), onde 13 a $25 \%$ das sementes testadas apresentaram o fitopatógeno, segundo esses autores as sementes estão diretamente envolvidas na continuidade do ciclo biológico dos fungos, passando de uma à outra 
geração, constituindo, também, o mais eficiente agente de transporte e disseminação. Desse modo, o tratamento das sementes antes do armazenamento é recomendado, independente das boas condições de umidade dos grãos.

Silva et al. (2019) constataram Aspergillus sp. variando de 20 a $24 \%$ e Rhizopus 0,5 a $10 \%$ das sementes em variedades de feijão-caupi. Silva et al. (2016) avaliando a incidência de patógenos em sementes de feijão provenientes de 37 cidades do Rio Grande do Norte, perceberam fitopatógenos em $94 \%$ das amostras de sementes, tendo o Aspergillus sp. incidência de $60 \%$.

O fungo Aspergillus sp. tem sido reportado com maior incidência na maioria dos trabalhos e são responsáveis pela maior parte da deterioração das sementes durante o armazenamento, bem como por reduzir demasiadamente a germinação destas. $\mathrm{O}$ gênero Rhizopus sp. tem sido apontando com baixa incidência comparada a outros fungos de armazenamento, esse gênero tem menor importância econômica em relação a danos às sementes, entretanto, devido a seu rápido crescimento, pode cobrir as sementes e dificultar a identificação de outros patógenos (TORRES e BRINGEL, 2005).

Os resultados do percentual de germinação das sementes de feijão-caupi, armazenadas em garrafa PET por 2 anos, indicam a necessidade de cuidado com o armazenamento dessas sementes por agricultores familiares, bem como atestam a necessidade de se avaliar a viabilidade do armazenamento nesses recipientes a longo prazo.

Pelo método do "Blotter-test" foi detectada a presença de Aspergillus sp. e Rhizopus sp. caracterizados como fungos de armazenamento e um patógeno (não identificado), que, juntos, comprometeram $94 \%$ das sementes do tratamento controle e 99,5 das sementes biocondicionadas com EM.

O uso de EM na dose de $1,2 \mathrm{~mL} \mathrm{~g}^{-1}$ de sementes de feijão-caupi, não reduziu a incidência dos fungos de armazenamento, tão pouco promoveu a germinação da semente. Sugere-se realizar novas pesquisas com diferentes dosagens e com sementes com menor tempo de armazenamento.

\section{Referências}

BRASIL. Ministério da Agricultura, Pecuária e Abastecimento. Manual de Análise Sanitária de Sementes. Ministério da Agricultura, Pecuária e Abastecimento. Secretaria de Defesa Agropecuária. Brasília: MAPA/ACS, 2009a. 200p.

BRASIL. Ministério da Agricultura, Pecuária e Abastecimento. Regras para análise de sementes. Secretaria de Defesa Agropecuária. Brasília, DF: MAPA/ACS, 2009b. 395 p.

BRAGANTINI, C. Alguns aspectos do armazenamento de sementes e grãos de feijão. Santo Antônio de Goiás: Embrapa Arroz e Feijão, 2005. 28 p. (Embrapa Arroz e Feijão. Documento Técnico, 187).

BONFIM, G. P. F; et al. Caderno dos microrganismos eficientes (E.M.). Instruções práticas sobre uso ecológico e social do EM. Viçosa: Univ. Fed. de Viçosa, 2011. 32p.

BORGES, E. S.; et al. Promoção do vigor em Pennisetum glaucum (L.) R. BR com diferentes concentrações de microorganismos eficientes (EM). Revista Brasileira de Agroecologia, v. 15, p. 148-154, 2020.

CARDOSO, M. J.; RIBEIRO, V. Q. Desempenho agronômico do feijão-caupi, cv. Rouxinol, em função de espaçamentos entre linhas e densidades de plantas sob regime de sequeiro. Revista Ciência Agronômica, v. 37, n. 01, p. 102-105, 2006.

CONAB. Acompanhamento da safra brasileira de grãos, v.8 - Safra 2020, n. 3- Terceiro levantamento, Brasília, p. 1-86, 2020.

FERNANDES, F. B. P.; et al. Efeito de manejos do solo no déficit hídrico, trocas gasosas e rendimento do feijão-decorda no semiárido. Revista Ciência Agronômica, vol.46. n.3,p.506-515. 2015.

HIMANGINI, J.; et al. Role of Effective Microorganisms (EM) in Sustainable Agriculture. International Journal of Current Microbiology and Applied Sciences, v.8, p.172-181, 2019.

MAGALHAES, L. D. S.; et al. Inoculação e coinoculação da soja com Bradyrhizobium japonicum, Azospirillum brasilense e microrganismos eficazes. Revista mirante v. 13, p. 66-80, 2020.

MAGUIRE, J. D. Speed of germination-aid selection and evaluation for seedling emergence and vigor. Crop Science, v. 2, n. 1, p. 176-177, 1962

MOWA E; MAASS E. The effect of sulphuric acid and effective microorganisms on the seed germination of Harpagophytum procumbens (devil's claw). South African Journal of Botany.v.83:p.193-199, 2012.

PORTO, L. S.; et al. Micro-organismos eficazes e Azospirillum brasilense: efeitos sobre a produtividade do milho.

Revista de Biotecnologia \& Ciência, v. 9, p. 11-21, 2020. 
R Core Team (2020). R: A language and environment for statistical computing. R Foundation for Statistical Computing, Vienna, Austria.

RODRIGUES, V. F, de O.; et al. Armazenamento de grãos em pequequenas propriedades de são francisco, paraíba, brasil. Colloquium Agrariae, v. 14, n.2, p. 35-47, 2018.

SANTOS, L. F.; et al. Effective microorganisms inoculant: Diversity and effect on the germination of palisade grass seeds. Anais da Academia Brasileira de Ciências, vol 92(Suppl. 1), e20180426. Epub March 09.2020.

SILVA, G. C.; et al. Incidência de fungos e germinação de sementes de feijão-caupi (Vigna unguiculata L. (Walp) tratadas com óleo de nim (Azadirachta indica A. Juss). Revista Brasileira de Plantas Medicinais, Botucatu , v. 16,n. 4, p. 850-855, 2014.

SILVA, F. N.; et al. Qualidade sanitária de sementes salvas de feijão-caupi utilizadas pelos agricultores do Rio Grande Norte. Revista de Ciências Agrarias - Amazon Journal of Agricultural and Environmental Sciences. v. 59.p. 60-65, 2016.

SILVA, F. H. A.; et al. Physical and physiological attributes of saved cowpea seeds used in the brazilian semi-arid region. Revista Caatinga, v. 32, p. 113-120, 2019.

SILVA, A O ; et al. Armazenamento de grãos na agricultura familiar: principais problemáticas e formas de armazenamento na região nordeste paraense. Research Society and Development. v.20. p. 01-11, 2021

TALAMINI, V.; et al. Qualidade fisiológica e sanitária de sementes de feijão (Phaseolus vulgaris L.) produzidas por agricultores familiares em Sergipe. Embrapa Tabuleiros Costeiros, 2010. 22p. (Boletim de Pesquisa e Desenvolvimento 62)

TORRES, S. B.; BRINGEL, J. M. M. Avaliação da qualidade sanitária e fisiológica de sementes de feijão macassar. Caatinga, v. 18, n. 2, p. 88-92, 2005.

ZUCCHI, T. D.; MELO, I. S. Controle biológico de Fungos aflatoxigêncos. In: BETTIOL,W.; MORANDI, M.A.B. Biocontrole de Doenças de plantas: uso e perspectivas. Embrapa Meio Ambiente, Jaguarúna, 2009. p. 69-94. 